\title{
Comparison Between Spread Patterns of Paint with Cup Sprayer and Atomization Tester.*
}

\author{
Gohei OSAME** and Masao HAGIHARA***
}

Atomization tester was used for a fundamental study of paints for electrical spraying. As it was observed that the specific resistance of the paint affects the extent of spread, a comparison test between the cup sprayer and the atomization tester was carried out to find a similarity between their sprays of the same paint.

Preliminary experiment. a) Extent of spread. In case of the atomization tester, the average horizontal diameter $(d)$ of 10 patterns sprayed with needle-pair terminal of $250^{\circ}$ (angle) and the average breadth $(l)$ of 3 doughnut-like patterns of the sprayer were determined.

b) Influence of paint quantity sprayed. In case of cup sprayer, $l$ became constant as soon as the sprayed quantity exceeded a certain value.

The sprayed quantity was not measured for atomization tester.

c) Influence of voltage. In case of atomization tester, $d$ increased with increasing voltage but $d$ became almost constant over a certain voltage, while in case of cup sprayer, $l$ decreased with increasing voltage.

Extent of spread of the sprayed paint. i) Influence of solvent. By changing the type of solvent, namely by varying physical properties of the paint, the extent of spread changed with electrical behaviors of the paint; the tester and the sprayer gave the same extent of spread.

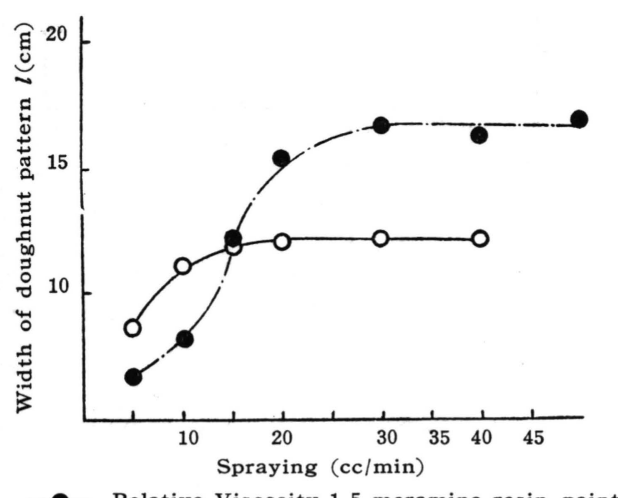

-O- Relative Viscosity 1.5 meramine resin paint

Fig. 2 Effect of spraying speed on spread of paint.

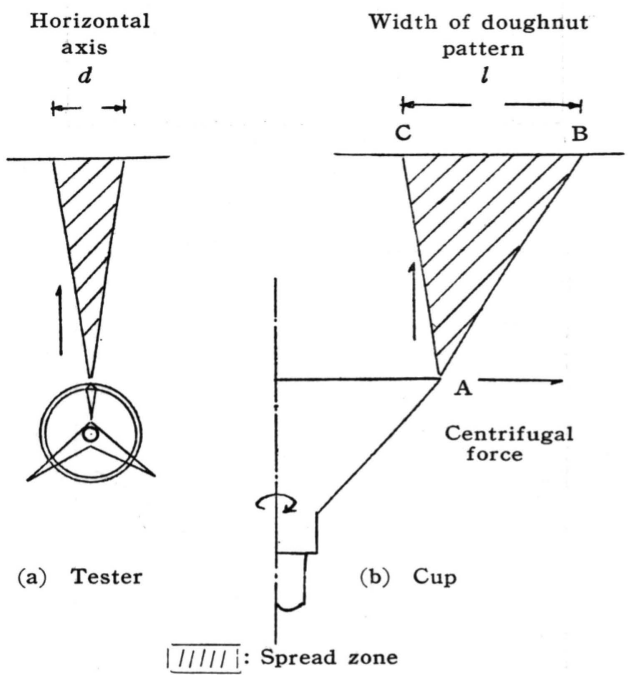

Fig. 1 Schematic representation of patterns from tester (a) and cup (b).

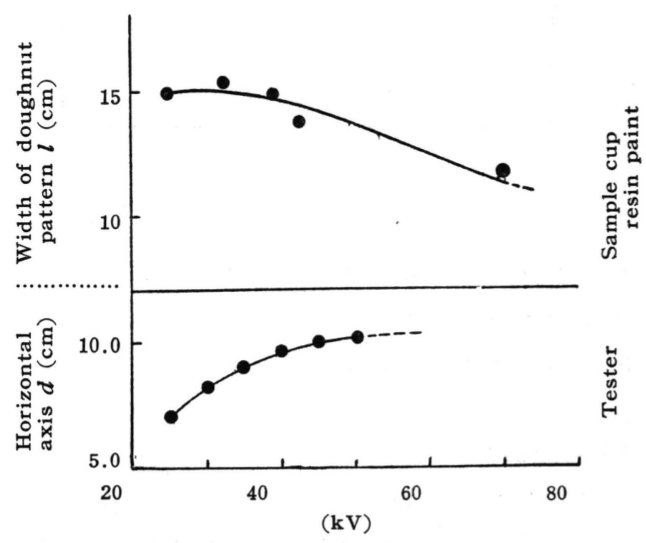

Fig. 3 Effect of high potential. Sample: Meramine resin paint.

* Atomization of Liquid by High Voltage (Part 3).

** Electrostatic Painting Machine Co., Ltd., Osaka

** Osaka University Hirakata-shi Osaka

The original written in Japanese can be seen in J. Electrochem. Soc. Japan, 26419 (1958). 


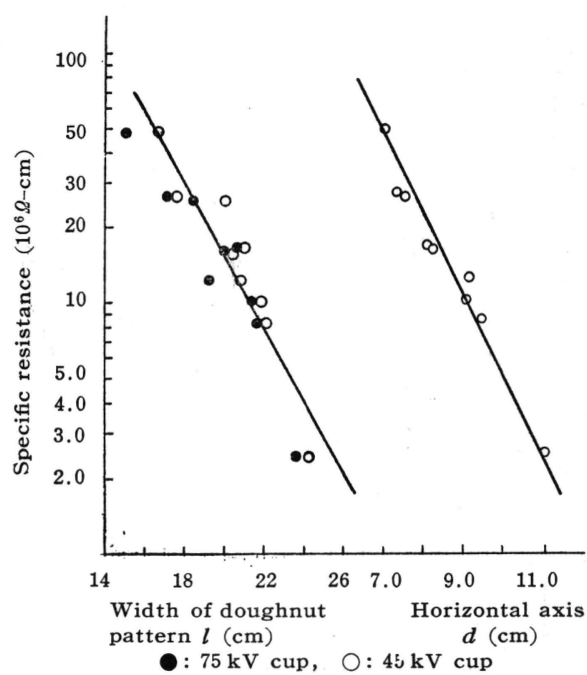

Fig. 4 Relation between spread and specific resistance.

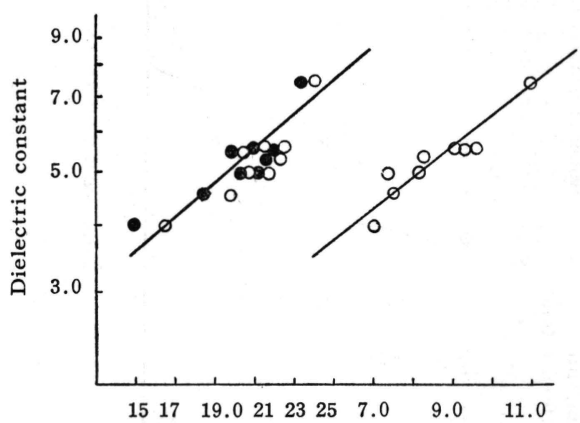

Width of doughnut Horizontal diameter pattern $l(\mathrm{~cm}) \quad d(\mathrm{~cm})$

- : $75 \mathrm{kV}, \bigcirc: 42 \mathrm{kV}$

Fig. 5 Relation between spread and dielectric constant.

ii) Influence of specific resistance. Under the same dielectric constant, $d$ changed with the logarithm of specific resistance.

iii) Influence of dielectric constant. Under the same specific resistance, $d$ and $l$ scarecely changed with the change of dielectric constant.

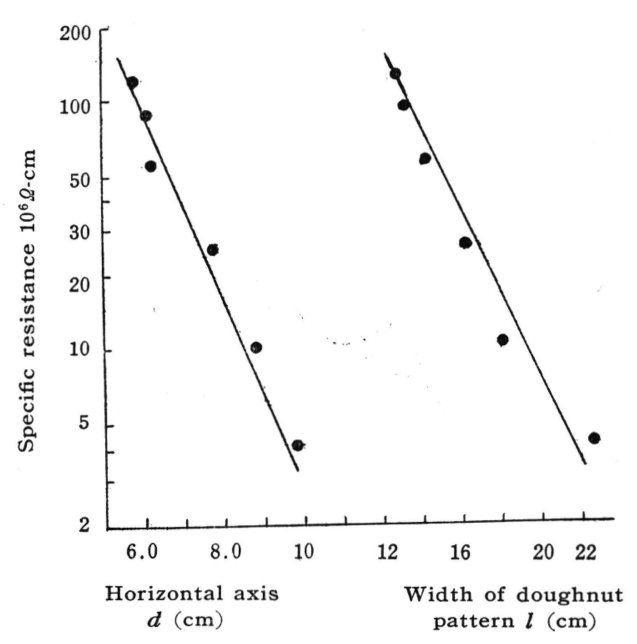

Fig. 6 Effect of specific resistance.

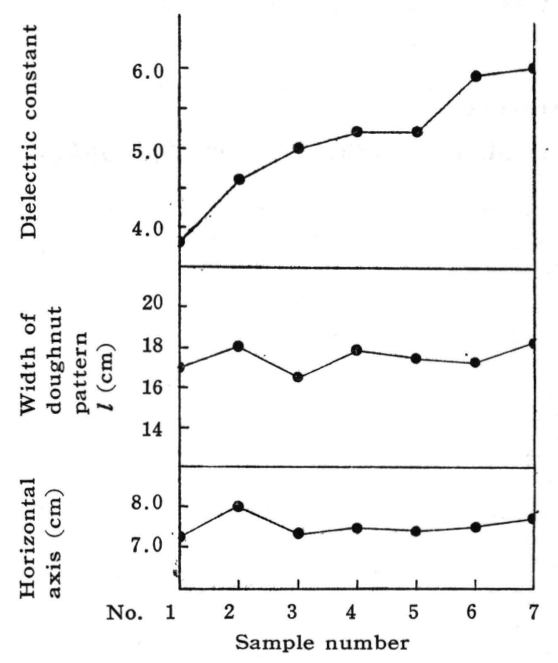

Fig. 7 Effect of dielectric constant.

iv) Influence of viscosity and specific gravity. Under the same specific resistance, $d$ and $l$ decreased with increasing viscosity, but there were no large variation within the viscosity change as in common paints.

Grain size distribution. Similar distribution of grain size was obtained with the tester and the sprayer. Therefore, the grain size distribution obtained with the tester was useful for finding the atomization with the cup sprayer. 


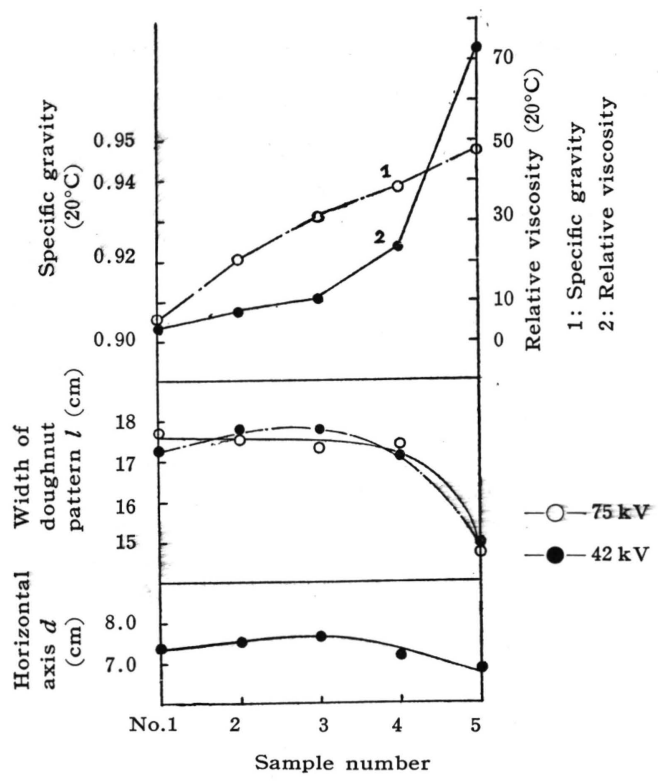

Fig. 8 Effect of viscosity and specific gravity.

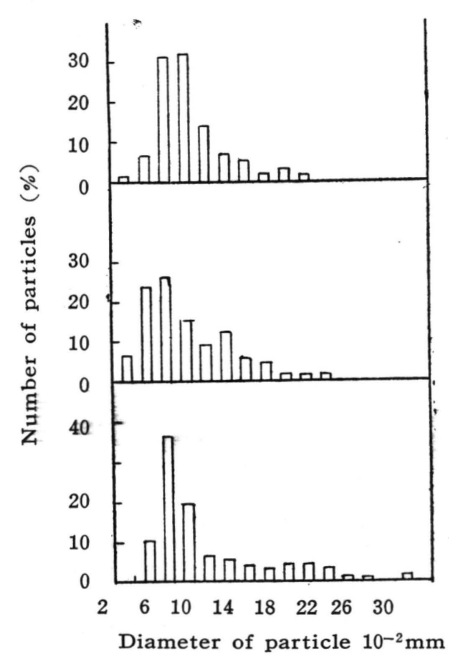

1. $75 \mathrm{KV}$ cup $52 \mathrm{cc} / \mathrm{min}$.

2. $42 \mathrm{KV}$ cup $52 \mathrm{cc} / \mathrm{min}$.

3. $42 \mathrm{KV}$ tester on spread of paint.

Conclusion. A big similarity in both patterns was found.

It was concluded that the behavior of paint particles leaving from the electrode of atomization tester was similar to that of the cup of the sprayer.

(Received Jan. 6, 1958)

\section{Literature :}

(1) M. Hagiwara: J. Chem. Ind. Japan, 16, 186 (1958) 